\title{
Do South Asian Nutrition Guidelines for Critically Ill Recommend Commercial Feeds or Blended Tube Feeds? - A Narrative Review
}

\author{
Asiya Abdul Raheem ', Barakatun-Nisak Mohd-Yusof', Lee Zheng-Yii³, Ali Abdulla Latheef ${ }^{4}$, Noor Airini
} Ibrahim $^{5 *}$

\begin{abstract}
:
In the previous years, blended tube feeds have been replaced by commercialized feeds; however, literature suggests that blended tube feeds are still being used to feed critically ill patients. Aim of this narrative review is to review the South Asian Critical Care Nutrition Guidelines type of feed recommendations. From the eight South Asian Countries, Critical Care Nutrition Guidelines are available only from Pakistan, India and Sri Lanka. Review of these guidelines indicate discrepancies with types of feed when compared to international guidelines such as nutrition guidelines from American Society for Parenteral and Enteral Nutrition. Indian and Sri Lankan Guidelines give way to administer Blended Tube Feeds in critically ill patients. There is no available literature to back their recommendation regarding use of blended tube feeds in critically ill patients. Reasons and evidence for recommendations of blended tube feeds need to be explored, while determining whether theses feeds are valid replacement for commercial enteral feeds.
\end{abstract}

Key words: Blended Tube Feed, Commercial Feed, Critically Ill, Feeding Product.

\section{Introduction}

South Asian countries include India, Pakistan, Bangladesh, Sri Lanka, Nepal, Afghanistan, Bhutan, and the Maldives, making up a total of eight nations. Of these countries, India is the most, and Maldives the least populated, with a population of 1276.2 million and 0.38 million in India and Maldives, respectively ${ }^{1}$. Information about the number of intensive care units (ICU) in these countries is limited. There are an estimated 70,000 beds in Intensive Care Units [ICU] all over India ${ }^{2}$. In Bangladesh, the first ICU was established in 1980. Since then the number of ICUs in Bangladesh increased over time, but the exact numbers is not clear ${ }^{3}$. Some other sources reported that they are about 100 ICUs in Sri Lanka ${ }^{4}, 33$ ICUs

1. Asiya Abdul Raheem, BSc, Department of Nutrition and Dietetics, Faculty of Medicine and Health Sciences, Universiti Putra Malaysia, e-mail: asy.abdulraheem@gmail.com

2. Dr. Barakatun-Nisak Mohd-Yusof, Associate Professor, Department of Nutrition and Dietetics, Faculty of Medicine and Health Sciences, Universiti Putra Malaysia. Email: bnisak@upm.edu.my

3. Lee Zheng Yii, MSc, Department of Anesthesiology, University of Malaya, email: zheng_yii@hotmail.com

4. Dr. Ali Abdulla Latheef, MBBS, MD, Department of Medicine, Indira Gandhi Memorial Hospital, e-mail: latheef@dhoonihuraa.com

5. Dr. Noor Airini Ibrahim, MBBS, MMed, EDIC, Anaesthesiology Unit, Faculty of Medicine and Health Sciences, Universiti Putra Malaysia.Email: airini@upm.edu.my

*Corresponding Author:

Dr. Noor Airini Ibrahim

MBBS, MMed, EDIC Anaesthesiology Unit,

Faculty of Medicine and Health Sciences

Universiti Putra Malaysia

Email: airini@upm.edu.my in Katmandu city, Nepal ${ }^{5}$. No exact data is available regarding number of ICUs in Afghanistan, but it has been reported that a 10-bed ICU was in the main referral hospital in Kabul, Afghanistan ${ }^{6}$. No data is available regarding the number of ICUs or ICU beds in Pakistan, Bhutan or Maldives.

These countries, except for Afghanistan and Bhutan have established critical care societies. Indian Society of Critical Care Medicine (ISCCM) was established in 1993. The members comprise of physicians, nurses, physiotherapists and other allied health professionals ${ }^{7}$. Similarly, Bangladesh Society of Critical Care Medicine comprising of physicians, nurses, physiotherapists and other allied health professionals was established in $2009^{8}$. On the other hand, Sri Lankan Society of Critical Care Medicine (SSCCM), established in 2002 is comprised mostly of doctors and nurses ${ }^{9}$. Critical Care Medicine Societies in Nepal and Maldives were formed in 2010 and 2017 respectively ${ }^{10,11}$. In terms of nutrition guidelines for ICU, only Sri Lanka, India and Pakistan have published their guidelines which are available online.

In the previous years, blended tube feeds (BTF) has been used extensively as the main source of feeding even in more advanced countries like United States (US) ${ }^{12}$. BTF is defined as any form of feed that is given by enteral route to a patient, and is not commercialized. These include soups, broths, liquefied foods, and juices. They are used to feed to the patient via the enteral route. Such feeds are either prepared in the hospital kitchen or at home by the patient relatives ${ }^{13,14}$.

Over the years, enteral nutrition has evolved so much that BTF have been replaced by commercialized feeds $(\mathrm{CF})^{12,15}$. This has led to the improvement in nutrition provision including providing feed that is nutritionally complete with less risk of microbial contamination and greater flexibility in modifying feeds according to patients' requirements ${ }^{12}$. In addition, $\mathrm{CF}$ are designed for different patient categories. 
Many types of CF are available including polymeric formula, high protein formula, immune-modular formula, high protein with low electrolytes formula, and low protein with low electrolyte formula. In addition, certain CF with a modular nutrition content, such as carbohydrate, protein and lipid modular are available. Such formula helps a dietitian to plan and tailor enteral nutrition for the patient according to their clinical needs to meet the nutrition goals of the patient ${ }^{15}$.

BTF, even if planned by a skilled dietitian may not be able to provide the required amount of nutrition ${ }^{16}$. In addition, nutritional balance of such feeds are questionable ${ }^{16}$. Although international dietary recommendations speak against the use of BTF in medically unstable patients ${ }^{17}$, use of BTF are reported in some countries such as Iran, Sri Lanka and India $^{13,14,18}$. In an article published in Nutrition Issues in Gastroenterology series \#176, it was mentioned that $70-75 \%$ of those recipes contain fluids, and micronutrients such as multivitamin, calcium, and other minerals may need to be added into $\mathrm{BTF}^{19}$. This raises questions whether BTF can be used as an alternative to $\mathrm{CF}$ for enteral nutrition in critically ill patients.

Previous reviews regarding BTF were done to determine the prevalence of blended tube feed use, and its safety, efficacy and implications for clinical practice, and explore whether $\mathrm{BTF}$ is valid as an alternative to $\mathrm{CF}$ in children fed via gastrectomy ${ }^{20}$. No reviews are available to explore whether BTF can be used as an alternative CF for enteral nutrition in the critically ill population of South Asia. Therefore, the purpose of this review is to identify enteral nutrition recommendation of the type of feed in the South Asian Enteral Nutrition Guidelines, and to identify whether such feeds are safe to be used as enteral nutrition in critically ill patients.

\section{Methods}

A literature search was done using electronic database sources such as Pubmed and Embase. Search was limited to articles in English language. All the studies mentioning BTF, liquidized feeds, kitchen feeds, and non-commercialized feeds were included. Due to the scarcity of literature on this topic, both hospitalized and home-bound patients were included. Critical care nutrition guidelines from South Asian countries were also included.

\section{Results}

A total of five papers are included in this review from which two are single center studies ${ }^{18,21}$ and three are nutrition guidelines ${ }^{13,14,22}$. From the single center studies, one study was an experimental design study done in critical care unit ${ }^{18}$. One study was an online survey among 433 parents of home fed children $^{21}$. The three enteral nutrition guidelines are from India, Sri Lanka and Pakistan 13,14,22. Guideline recommendations of type of feed is summarized in Table 2 in the annex of this article.

\section{Effectiveness of Blended Tube Feeds for Enteral Nutrition}

Number of studies done using blended tube feeds in critically ill patients is extremely rare. We identified only 2 studies meeting criteria from about 27 search items. The first study was conducted in Tabriz Iran in a total of 80 critically ill patients. They were randomly allocated into two groups - one group was fed with $\mathrm{CF}$ and the other with hospital prepared BTF. The researchers investigated the effects of standard formula versus the blended tube feeds on serum albumin and calcium levels of the subjects. They estimated that the blended tube feeds would provide $0.7 \mathrm{kcal} / \mathrm{ml}$ with $50-60 \%$ from carbohydrates, $25-35 \%$ from fats and $15-20 \%$ from proteins, and $\mathrm{CF}$ would provide $1 \mathrm{kcal} / \mathrm{ml}$ with $55 \%$ from carbohydrates, $30 \%$ from fats and $15 \%$ from proteins. Biochemical investigations done at day 7 of initiating feeds demonstrated that there was a significant difference in serum albumin and calcium between CF and BTF. Although an increase in albumin level is observed in both groups, the group fed with $\mathrm{CF}$ showed a statistically higher increase compared to group fed with BTF. Calcium was increased in group fed with CF, but decreased in group fed with $\mathrm{BTF}^{18}$.

Another study was an online survey that explores parents' reported experience with $\mathrm{CF}$ and BTF. $49.5 \%$ of the parents reported to use BTF, and $50.5 \% \mathrm{CF}$ exclusively for their home enterally fed children. Reasons reported by parents for choosing BTF were: 1 . BTF is more natural than $\mathrm{CF}, 2$. BTF is better tolerated than $\mathrm{CF}, 3$. Do not like the ingredients in $\mathrm{CF}$, 4. To provide family foods, 5 . Increase oral intake, 6 . Prevent allergies, 7. BTF is less costly. Reasons given by parents who chose $\mathrm{CF}$ were not knowing how to prepare BTF, time constraint, inconvenience of using BTF, cost and safety concerns. The study also reported that those children who were fed with BTF met growth goals more than CF fed children, and those who were fed with BTF had less nausea, vomiting, fever, bloating, diarrhea, constipation and pain ${ }^{21}$.

\section{South Asian Nutrition Guideline Recommendations on Enteral Nutrition Feeding Products}

Among the eight South Asian Countries, Critical Care Nutrition Guidelines are available only in Pakistan, India and Sri Lanka ${ }^{13,14,22}$. Table 2 in Appendix summarizes key recommendations in these guidelines regarding type of feed.

Pakistan have ICU feeding protocol instead of guidelines. In their protocol, a flow chart indicating how to choose each of the feeding product, with the name of the product is mentioned specifically. The protocol recommended to initiate standard polymeric formula for most patients. Hydrolyzed formula are recommended in patients with malabsorption, and other disease-specific formula according to patients' clinical presentation $^{22}$. There is no mention of BTF in their protocol.

The Indian critical care nutrition guidelines recommended to use polymeric formula to initiate feeds in critically ill patients. The Indian guidelines stated explicitly that BTF deliver lesser energy and protein than CF. They also stated that the problem of nutrients inconsistency can be prevented by avoiding $\mathrm{BTF}^{13}$.

Sri Lankan Guidelines on Nutritional Support in ICU is totally different from the above mentioned guidelines as they recommend to use enteral feeds prepared in-house, and they have provided charts of nutritional values of food. Moreover, they also allow relatives to bring home-prepared feeds for 
critically ill patients. However, they advised dietitians' evaluation for those who prefered to bring home-made feeds. In their guideline $\mathrm{CF}$ are mentioned as something that may be added to where appropriate and available ${ }^{14}$.

\section{Discussion}

Three critical care nutrition guidelines from South Asian Countries were sought from this literature search. The three guidelines are from Pakistan, India and Sri Lanka ${ }^{13,14,22}$. Recommendation regarding type of feed in Pakistan Critical Care Nutrition Guideline is aligned with recommendations given in international critical care nutrition guidelines such as American Society for Parenteral and Enteral Nutrition [ASPEN] Guideline for Nutrition in Critically Ill Patient ${ }^{23}$. Similar to ASPEN, Pakistan nutrition guidelines recommends to initiate feeds in general critically ill patient with standard polymeric formula. However, Indian Critical Care Nutrition Guideline and Sri Lankan Critical Care nutrition guideline formulated in 2018 and 2014 respectively gives way to administer BTF in critically ill patients ${ }^{13,14}$. Although Indian guideline was formulated recently ${ }^{13}$, Sri Lankan guideline was formulated 5 years ago, and was recommended to be reviewed in $2016^{14}$.

This raises concern with respect to risk of contamination and nutritional content of feeds. In a study done to evaluate microbial contamination of blended tube feeds and commercial feeds using 13 blended tube feed samples and 12 commercial samples, the researchers found that both types of samples were susceptible to contamination unless strict safety handling procedures are $\mathrm{met}^{24}$. Similar results were found in a study conducted in $\mathrm{US}^{26}$. In both of these studies, BTF was prepared in hospital kitchen with food safety protocols being followed ${ }^{24,26}$. If the feeds for critically ill patients are allowed to be prepared at home as stated in Indian and Sri Lankan Guidelines $^{13,14}$, safety in food handling and preparation is questionable. Food safety can also be questionable even if BTF is prepared in a hospital unless food safety protocols are strictly followed. Literature reviews revealed that hospital prepared BTF itself can contain coliforms ${ }^{27}$.

Another concern is whether BTF can provide the nutritional requirements of critically ill patients. In a research done to evaluate the nutritional content and viscosity of hospital-prepared BTF using feeds prepared in-house kitchen of 4 different hospitals in Philippines, the researchers discovered that the in-house prepared feeds had unpredictable nutritional values and varying consistencies although they were prepared according to instructions of dietitians ${ }^{16}$. The providers of BTF in this study claimed that the feeds were nutritionally complete ${ }^{6}$. Vitamin levels and trace elements such as Zinc were undetectable in many samples ${ }^{16}$. In addition, there were marked discrepancies between expected and measured values with respect to energy and macronutrients ${ }^{16}$. Furthermore, the viscosity of blended tube feeds was very high and varied ${ }^{16}$. High viscosity can cause tube blockage during BTF delivery. In addition, preparation of BTF can be time consuming.

A rapid review was done to explore whether BTF is a valid alternative to $\mathrm{CF}$ in children fed enterally via gastrectomy.
This review reported that BTF had variable nutrient compositions. This variation can be due to geographical source of food, the season and stage of maturity of the natural produce, and storage and method of cooking. It was reported that such feeds would not be able to provide full nutrition even in Home Enteral Nutrition [HEN] patients. They recommended to conduct more research to explore the risks, benefits, impacts and outcomes of $\mathrm{BTF}^{25}$.

It is evident that in contrast to international guidelines, BTF are still being used to feed critically ill patients in South Asian countries. There are no studies that support the use of BTF. This raises questions why it is still then being practiced. Is it more natural, better tolerated, able to prevent food allergy, or less costly? The reasons for choosing BTF were not mentioned in the guidelines. No study has been done to assess knowledge, attitude, practice or behavior of ICU staff regarding standard nutritional management and recent ICU guidelines in South Asian countries that can explain why BTF are still being used in the ICU. If cost is the reason for providing BTF, there is no cost analysis papers available from these countries to support their reason to recommend BTF.

\section{Conclusion}

This review found that some guidelines from South Asian countries (i.e. Sri Lanka and India) allow the use of BTF in critically ill patients. Recommendation to use of BTF in South Asian countries in this era is a huge concern. Further investigation needs to be done to understand the safety of BTF and the reasons behind their use. A randomized controlled trial to investigate the difference in mortality outcomes between patient fed with CF and BTF is warranted.

\section{References}

1. Sawe, B. E. (2018). South Asia: Constituent Countries And Their Populations And Economies. Retrieved: September 15, 2019, from https://www.worldatlas.com/articles/the-population-and-economyof-the-south-asian-countries.html

2. Jayaram, R., \& Ramakrishnan, N. (2008). Cost of intensive care in India. Indian $J$ Crit Care Med, 12(2), 55-61. doi: 10.4103/0972-5229.42558: 10.4103/0972-5229.42558

3. Mostafa, N. (2018). Critical Care Medicine: Bangladesh Perspective. Adv $J$ Emerg Med, 2(3), 1-2. doi: 10.22114/ajem.v0i0.79

4. Pinto, V., \& Kudavidanage, B. (2018). Critical care in Sri Lanka the past, present and future. Retrieved September 15, 2019 from http://www.sundaytimes.lk/180610/sunday-times-2/critical-care-insri-lanka-the-past-present-and-future-297394.html

5. Acharya, S. P. (2013). Critical care medicine in Nepal: where are we? Int Health, 5(2), 92-95. doi: 10.1093/inthealth/iht010

6. Lin, A. H., Glover, D. E., \& Myers, J. S. (2011). An Overview of Afghan National Army Critical Care Capabilities. Military Medicine, 176(9), 1003-1006. doi: 10.7205/milmed-d-11-00036

7. Indian Society of Critical Care Medicine [ISCCM]. (2018). About ISCCM. Retrieved September 15, 2019 from http://www.isccm.org/

8. Bangladesh Society of Critical Care Medicine [BSCCM]. (2019). Home: Bangladesh Society of Critical Care Medicine. Retrieved September 15, 2019 from http://www.bsccm.net/ 
9. Sri Lankan Society of Critical Care Medicine [SSCCM]. (2017). Sri Lankan Society of Critical Care and Emergency Medicine. Retrieved September 15, 20119 from http://www.ssccem.com/

10. Nepalese Society of Critical Care Medicine [NSCCM]. (2018). Nepalese Society of Critical Care Medicine - NSCCM - Home. Retrieved September 15, 2019 from http://www.nsccm.org.np/

11. Maldives Society of Critical Care and Emergency Medicine [MSCCEM], (2017). Retrieved September 15, 2019 from: https://web.facebook.com/pg/msccem.01/about/?ref=page_internal

12. Campbell, S. M., (2006). An Anthology of Advances in Enteral Tube Feeding Formulations. Nutr Clin Pract, 21(4). $10.1177 / 0115426506021004411$

13. Mehta, Y., Sunavala, J., Zirpe, K., Tyagi, N., Garg, S., Sinha, S., . . Kadhe, G. (2018). Practice guidelines for nutrition in critically Ill patients: A relook for Indian scenario. Indian J Crit Care Med,22(4), 263. doi:10.4103/ijccm.ijccm_3_18

14. Faculty of Critical Care \& Nutrition Division of Ministry of Health Sri Lanka (2014). Guidelines on Nutritional Support in ICU. The College of Anesthesiologist in Sri Lanka \& Ministry of Health Sri Lanka

15. Chernoff, R., (2006). History of Tube Feeding - An Overview of Tube Feeding: From Ancient Times to the Future, Nutr Clin Pract, 21(4), $408-410$.

16. Sullivan, M. M., Sorreda-Esguerra, P., Platon, M. B., Castro, C. G., Chou, N. R., Comer, G. M. \& Alarcon, P., (2004). Nutritional analysis of blenderized enteral diets in the Philippines, Asia Pac $J$ Clin Nutr, 13(4), 385 - 390

17. Brown, B, Roehl, K. \& Betz, M., (2014). Enteral Nutrition Formula Selection: Current Evidence and Implications for Practice, Nutr Clin Pract, 30(1), 72 - 85. Doi: 10.1177/0884533614561791.

18. Jazayeri, S. M. H. M. \& Ostadrahimi, A., (2016). Standard enteral feeding improves nutritional status compared with hospital prepared blended formula among Intensive Care Unit (ICU) patients, Progress in Nutrition, 18(1), $22-25$.

19. Parrish, C. R., (2018). Blenderized feeding options - the sky's the limit, Nutrition Issues in Gastroenterology, series \#176

\section{Appendix}

Table 1: Studies investigating blended tube feed

\begin{tabular}{|c|c|c|c|c|c|}
\hline Author & Study Design & Population & Sample Size & What was investigated & Outcome \\
\hline $\begin{array}{l}\text { Jazayeri et al., } \\
2016\end{array}$ & Intervention & ICU - adults & $\begin{array}{l}40 \mathrm{BTF} \\
40 \mathrm{CF}\end{array}$ & $\begin{array}{l}\text { Outcome } \\
\text { albumin and calcium } \\
\text { level) of BTF vs CF in } \\
\text { ICU }\end{array}$ & $\begin{array}{l}\text { - Serum albumin was raised in } \\
\text { both groups, but serum } \\
\text { albumin was raised } \\
\text { statistically higher in CF } \\
\text { group compared to BTF group } \\
\text { - Calcium was decreased in } \\
\text { BTF group, but raised in CF } \\
\text { group }\end{array}$ \\
\hline
\end{tabular}

Jhonson et al., Online survey Parents of 433

2017 home fed

children
$49.5 \% \mathrm{BTF}$

$50.5 \% \mathrm{CF}$
Explore parents reported experience with BTF
Reasons for choosing BTF: more natural, better tolerance, does not like $\mathrm{CF}$ ingredients, provide family foods, increase oral intake, prevent allergies, less costly

Reasons for not choosing BTF: not knowing how to prepare, time constrain, inconvenience, cost, safety concerns

Abbreviations: ICU (Intensive Care Unit), BTF (Blended Tube Feeds), CF (Commercial Feeds) 
Bangladesh Crit Care J March 2020; 8 (1): 48-52

Table 2: Guidelines recommendations regarding type of feed in critically ill patient

\begin{tabular}{|c|c|c|c|}
\hline Guideline & Country & Year & Recommended types of feeds \\
\hline \multirow{3}{*}{$\begin{array}{l}\text { American Society for Parenteral } \\
\text { and Enteral Nutrition }\end{array}$} & America - & 2016 & \\
\hline & International & & $\begin{array}{l}\text { To initiate enteral nutrition with standard polymeric formula in } \\
\text { most patients }\end{array}$ \\
\hline & & & $\begin{array}{l}\text { Immune modulating formula to be reserved for patients with } \\
\text { Traumatic brain injury and surgical critically ill patients }\end{array}$ \\
\hline \multirow{3}{*}{$\begin{array}{l}\text { Evidence-based Feeding } \\
\text { Protocols in intensive } \\
\text { care units }\end{array}$} & Pakistan & 2016 & \\
\hline & & & $\begin{array}{l}\text { To initiate enteral nutrition with standard polymeric formula in } \\
\text { most patients }\end{array}$ \\
\hline & & & Use hydrolyzed formula in malabsorption \\
\hline \multirow{4}{*}{$\begin{array}{l}\text { Practice Guideline for Nutrition } \\
\text { in Critically Ill Patients }\end{array}$} & l. & P & Use other disease-specific formula in special cases \\
\hline & mala & 2018 & Standard polymeric formula in critically ill patients \\
\hline & & & $\begin{array}{l}\text { Compared to commercialized feeds, blenderized feeds deliver } \\
\text { lesser energy and protein - inconsistency in nutrients can be } \\
\text { avoided by using standard polymeric formula feeds }\end{array}$ \\
\hline & & & Routine use of specialty formula to be avoided \\
\hline \multirow{5}{*}{$\begin{array}{l}\text { Guidelines on Nutritional } \\
\text { Support in ICU }\end{array}$} & Sri Lanka & 2014 & \\
\hline & & & $\begin{array}{l}\text { Enteral feeds prepared in-house (chart of recipes provided in the } \\
\text { guideline) }\end{array}$ \\
\hline & & & Commercial products can be added as appropriate where available \\
\hline & & & $\begin{array}{l}\text { Relatives of patients admitted in intensive care unit can be given } \\
\text { the choice to bring feed prepared at home with feed preparation } \\
\text { recipe and instructions given by the dietitian - a list of feed recipes } \\
\text { are given at the annex of guideline. The recipes call for feeds that } \\
\text { require fresh produce to be cooked at home and then blended }\end{array}$ \\
\hline & & & Consider polymeric preparation \\
\hline
\end{tabular}

